\title{
Communications
}

\section{A Facile and Efficient Deoxygenation of Sulfoxides with $\mathrm{Mo}(\mathrm{CO})_{6}$}

\author{
Byung Woo Yoo, Min Suk Song, and Min Chol Park \\ Deparment of Advanced Materials Chemistry, Korea Cniversin, Jochin'on. Chungnam $339-700$, Korea \\ "E-mail: bu'voóakoreack k" \\ Received October 27. 2006
}

Key Words : Deoxygenation, Sulfoxides, Sulfides. Molybdenum hexacarbonyl

The deoxygenation of sulfoxides to sulfides is a valuable transformation in the application of organosulfur compounds in organic synthesis. Accordingly a good number of methods have been developed for the reduction of sulfoxides to the corresponding sulfides.' However, they often suffer from serious disadvantages. such as functional group incompatibility. difficult work-up procedures. harsh reaction conditions. or not readily available reagents. Further some of these methods are associated with limitations regarding low yields. prolonged reaction times. and intricate procedures. Therefore. there still exists a search for new improved methods based on easily accessible reagents and operationally simple procedures for the reduction of sulfoxides. The use of oxophilic dblock metals have become important in deosygenation of various types of organic molecules. ${ }^{2}$ In this regard, the selective reduction of azides, nitro compounds and hydroxylamines to amines and deoxygenation of epoxides have been accomplished with $\mathrm{Mo}(\mathrm{CO})_{6 .}{ }^{3}$ Recently, we have reported that molybdenum hexacarbonyl reagent is useful for the mild and selective deoxygenation of N-O bond on amine- $N$ oxides. These results prompted us to extend the studies on the reducing abilities of this reagent. In this commutuication. we wish to report a facile and efficient deoxygenation method for sulfoxides using the cheap metal carbonyl. molybdenum hexacarbonyl under mild conditions. The chemistry of $\mathrm{Mo}(\mathrm{CO})_{6}$ is one of the current interest in organic synthesis due to the ease of handling. mild reaction conditions, and availability (it is commercially available as a stable crystalline solid) : Particularly. Mo(CO) 6 has been used to reduce the N-O bonds of isoxazoles. ${ }^{6}$ isoxazolines. ${ }^{7}$ isoxazolidines ${ }^{8}$ and 1.2-oxazines. ${ }^{9}$ To the best of our knowledge, there have been no previous studies on the deoxy genation of sulfoxides with $\mathrm{Mo}(\mathrm{CO})_{6}$. We have investigated the reactions of $\mathrm{Mo}(\mathrm{CO})_{6}$ with structurally different sulfoxides and found that they can be conveniently reduced to the corresponding sulfides under neutral and mild conditions (eq. 1). In comparison with other procedures. $\mathrm{Mo}(\mathrm{CO})_{6}$ reduces sulfoxides

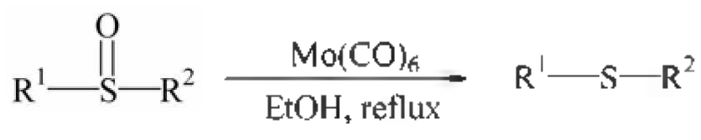

more efficiently in higher yields (84-96\%) and showed a good chemoselectivity under mild conditions. The reactions were clean. high-yielding and completed within 2-4 hours depending on the substituents on the aryl rings. ${ }^{10}$ The sulfoxides are prepared by oxidation of the corresponding sulfides with sodium metaperiodate in aqueous methanol. ${ }^{1]}$ The functional group tolerance of this method is evident from entries 3-7 which show that bromo. clloro. methoxy. aldehyde, and vinyl functionalities are intact under the reaction conditions. All the compounds obtained showed IR. NMR and mass spectral data compatible with the structure. In order to assess the generality of the process. the reaction was studied with a variety of sulfoxides. Under the optimized conditions. the deoxygenation of several kinds of sulfoxides was carried out. The results are summarized in Table 1. As can be seen from Table 1 . the reaction is equally applicable to dialkyll diaryl and aryl alkyl sulfoxides. Thus we have been able to demonstrate the utility of readily available $\mathrm{Mo}(\mathrm{CO})_{6}$ as a convenient reagent for effecting chemoselective deoxygenation of sulfoxides. Although the mechanism of the reaction is not yet clarified. it can be rationalized as the result of a two-stage process. A possible mechanism for the reductive $\mathrm{S}-\mathrm{O}$ bond cleavage of the

Table 1. Deoxygenation of sulfoxides to sultides with $\mathrm{Mo}(\mathrm{CO})_{0}$

\begin{tabular}{|c|c|c|c|c|c|}
\hline Entry & $\mathrm{R}^{\mathrm{l}}$ & $\mathrm{R}^{2}$ & Products & $\begin{array}{l}\text { Time } \\
\text { (hr) }\end{array}$ & $\begin{array}{l}\text { Yield } \\
(\%)^{4}\end{array}$ \\
\hline $\mathrm{l}$ & $\mathrm{Ph}$ & Ph & PhSPh & 2.0 & 92 \\
\hline 2 & $\mathrm{Ph}$ & $\mathrm{CH}_{3}$ & $\mathrm{PhSCH}_{3}$ & 2.5 & 96 \\
\hline 3 & $4-\mathrm{BrC}_{6} \mathrm{H}_{4}$ & $\mathrm{CH}_{3}$ & $4-\mathrm{BrC}_{6} \mathrm{H}_{4} \mathrm{SCH}_{3}$ & 3.0 & 91 \\
\hline 4 & $4-\mathrm{ClC}_{6} \mathrm{H}_{4}$ & $4-\mathrm{ClC}_{5} \mathrm{H}_{4}$ & $\left(4-\mathrm{ClC}_{6} \mathrm{H}_{4}\right)_{2} \mathrm{~S}$ & 3.0 & 84 \\
\hline 5 & $4-\mathrm{CH}_{3} \mathrm{OC}_{6} \mathrm{H}_{4}$ & $4-\mathrm{CH}_{3} \mathrm{OC}_{5} \mathrm{H}_{4}$ & $\left(4-\mathrm{CH}_{3} \mathrm{OC}_{6} \mathrm{H}_{4}\right)_{2} \mathrm{~S}$ & 4.0 & 93 \\
\hline 6 & $4-\mathrm{CHOC}_{6} \mathrm{H}_{4}$ & $\mathrm{CH}_{3}$ & $4-\mathrm{CHOC}_{6} \mathrm{H}_{4} \mathrm{SCH}_{3}$ & 2.0 & 88 \\
\hline 7 & $\mathrm{Ph}$ & $\mathrm{CH}=\mathrm{CH}_{2}$ & $\mathrm{PhSCH}=\mathrm{CH}_{2}$ & 2.5 & 85 \\
\hline 8 & $4-\mathrm{CH}_{3} \mathrm{C}_{6} \mathrm{H}_{4}$ & $\mathrm{CH}_{3}$ & $4-\mathrm{CH}_{3} \mathrm{C}_{4} \mathrm{H}_{4} \mathrm{SCH}_{3}$ & 3.0 & 89 \\
\hline 9 & $4-\mathrm{CH}_{3} \mathrm{C}_{6} \mathrm{H}_{4}$ & $4-\mathrm{CH}_{3} \mathrm{C}_{6} \mathrm{H}_{4}$ & $\left(4-\mathrm{CH}_{3} \mathrm{C}_{4} \mathrm{H}_{4}\right)_{2} \mathrm{~S}$ & 3.0 & 94 \\
\hline 10 & $\mathrm{Ph}$ & $\mathrm{CH}_{2} \mathrm{CH}_{3}$ & $\mathrm{PhSCH}_{2} \mathrm{CH}_{3}$ & 2.0 & 91 \\
\hline 11 & $\mathrm{PhCH}_{2}$ & $\mathrm{PhCH}_{2}$ & $\left(\mathrm{PhCH}_{2}\right)_{2} \mathrm{~S}$ & 3.0 & 86 \\
\hline 12 & $\mathrm{PhCH}_{2}$ & $\mathrm{Ph}$ & $\mathrm{PhCH}_{2} \mathrm{SPh}$ & 2.0 & 87 \\
\hline 13 & $\mathrm{nC}_{4} \mathrm{H}_{\mathrm{u}}$ & $\mathrm{nC}_{4} \mathrm{H}_{4}$ & $\left(\mathrm{nC}_{4} \mathrm{H}_{4}\right)_{2} \mathrm{~S}$ & 4.0 & 88 \\
\hline
\end{tabular}

Isolated yields. 

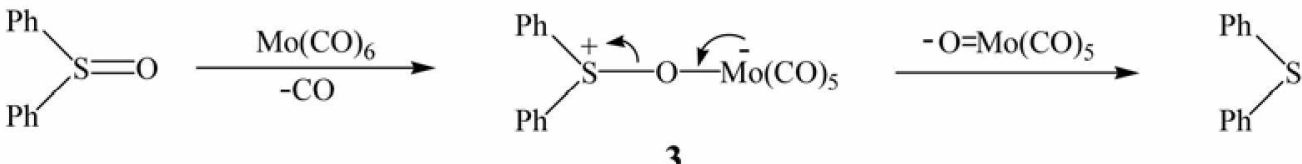

Scheme 1

sulfoxide is outlined in Scheme 1, using diphenylsulfoxide as the substrate. In the first step. the reaction was assumed to proceed by loss of $\mathrm{CO}$. Then the oxygen of the sulfoxide coordinates to $\mathrm{Mo}(\mathrm{CO})_{6}$ to give the complex 3 and facilitate the $\mathrm{S}-\mathrm{O}$ bond cleavage. In the subsequent step. cleavage of the $\mathrm{S}-\mathrm{O}$ bond leads to the formation of the corresponding sulfide. The notable advantages of the present procedure are the ease of manipulation. the mild reaction condition. the high yields and the tolerance of several labile functional groups.

In conclusion, we have demonstrated the first examples of $\mathrm{Mo}(\mathrm{CO})_{6}$-mediated reductive $\mathrm{S}-\mathrm{O}$ bond cleavage reactions of sulfoxides. We believe that this novel procedure will present a useful and attractive alternative to the existing methods for the deoxygenation of sulfoxides to sulfides. Further investigations of more useful applications are currently in progress.

Acknowledgement. This work was supported by the Brain Korea 21 Project in 2006.

\section{References}

1. (a) See for a review: Madesclaire. M. Tetahedron 1988. 21,6537. (b) See for an earlier review: Drabowicz. I. Togo. H.: Mikolajczyk. M.: Oae. S. Org. Prep. Proc. Int. 1984. 16. 171. (c) Schmizu, M: Slibura, K.: Hayakawa, R. Smlet 2000. 1437. (d) Khurana. J. M. Tetrahedron Lett. 1998. 39. 3829. (e) Yadav. J. S.: Reddy. B. V. S.: Srinivas. C.: Srihari. P. Swlet 2001. 854. (f) Balicki. R. Sinthesis 1991. 155. (g) Miller. S. J.: Collier. T. R.: Wu, W. Tetrahedron Lett 2000, H1, 3781. (1) Firoluzabadi, H: Karimi. B. Symthesis 1999. 500 .

2. Cintas. P. Activated Metals in Organic Symhesis: CRC: Boca
Raton. 1993.

3. (a) Patra, A.; Bandyopadhyay, M; Mal, D. Tetrahedron Lett 2003. Ht, 2355. (b) Iver. S. Kulkarni. G. M. Smml. Commum. 2004. 3t, 721. (c) Moody. C. J. Chem. Commm. 2004, 1341. (d) Guama. A.: Guidi. A.: Goti. A.: Brandi. A.: De Sarlo. F. Symthesis 1989. 175 .

4. Yoo. B. W.: Choi. T. W.: Yoon. C. M. Tetrahedron Lett $2005 .+6$. 125 .

5. (a) Harvey, D. F, Sigano. D. M. Chem. Rev 1996, 96, 271 and references therein. (b) Harvey, D. F.; Brown. M. F. Temahedron Lett. 1990. 31.2529. (c) Barluenga. T.: Fananas. F. J.: Tetrohedron 2000. 56. 4597. (d) Shvo. Y.: Greetr. R. J. Organontet. Chent. $2003,675,77$

6. (a) Nitta. M.: Kobavashi, T. J. Chem. Soc. Perkin Trons. I 1985. 1401. (b) Donate, D; Ferrini, S.: Fusi, S.: Ponticelli, F. d. Heterocycl. Chem. 2004, 41.761.

7. (a) Baraldi. P. G.: Barco. A.: Benetti. S.: Mantredini. S.: Simoni. D. Smthesis 1987. 276. (b) Trost. B. M.: Li. L.: Guile. S. D. J. Ant. Chent Soc. 1992. 114.8745. (c) Tranmer. G K.: Tam. W. Org Lett. 20012. +.4101 .

8. Cicehi, S.; Goti. A.: Brandi. A.: Guama, A.: De Sarlo. F. Tetrahedron Lett 1990. 31. 3351.

9. (a) Zimmer. R.: Reissig. H. U. J. Org. Chem. 1992, 57.339. (b) Li. F.: Brogant. I. B.: Gage. I. L.: Zhang. D.: Miller. M. J. J. Org. Chent 2004. 69.4538.

10. A typical procedure for the deoxygenation of sultoxides is as follows: To a solution of diphenylsul foxide (202 $\mathrm{mg}, 1.0 \mathrm{mmol}$ ) in ethanol $(10 \mathrm{~mL})$ is added molybdenum hexacarbonyl $(264 \mathrm{mg} .1 .0$ mmol). The misture was reflused for 2 hr and followed by TLC. Atter completion of the reaction. the resulting misture was concentrated under reduced pressure. extracted with ether. washed with water. dried over $\mathrm{MgSO}_{4}$. and concentrated. The residue was purified by silica gel column chromatography (hexane:ethyl acetate $=1: 1)$ to aftord diphenylsulfide $\left(172 \mathrm{mg} .92^{2} \cdot 0\right)$.

11. Iogels Textbook of Practical Onganic Chemismy. Sth ed.: p 792 